\title{
Erythema dyschromicum perstans
}

\author{
Manjari Basu ${ }^{1}$, Swapan Ray $^{2}$, Kuntal Kanti Das ${ }^{3}$, Dinobondhu Sahana ${ }^{3}$, Priti Khemka ${ }^{3}$, Sukanta \\ Bhattacharya $^{4}$
}

Sri Lanka Journal of Child Health, 2012; 41(3): 143-144

(Key words: Erythema dyschromicum perstans; hypermelanosis)

\section{Introduction}

There are several causes of diffuse hyperpigmentation of skin in infants ${ }^{1}$. These include carbon baby syndrome, congenital diffuse melanosis, familial progressive hyperpigmentation, postinflammatory pigmentation, Addison disease, haemochromatosis, vitamin $\mathrm{B} 12$ and niacin deficiency $^{1}$. A rare condition is erythema dyschromicum perstans or ashy dermatosis.

\section{Case report}

A 2 year old boy, born of a $3^{\text {rd }}$ degree consanguineous marriage presented with a history of generalized increase in pigmentation since 3 months of age. Perinatal period was uneventful but mother had a past history of giving birth to an anencephalic baby. Growth and development of the baby was normal. Family history of similar illness was absent.

The darkening of skin first appeared over the face as a grayish macule with elevated reddish border and gradually progressed to involve limbs, abdomen, back, palms and soles and coalesced with each other causing generalized hyperpigmentation (Figure 1).

Skin texture, sweat secretions and mucosa were normal. Patient had no other symptoms. Eye examinations and other systemic examinations were normal. There was no history of discolouration of urine or photosensitivity.

The haemoglobin level was $10.7 \mathrm{~g} \%$ and the mean corpuscular volume 69. Other blood counts were normal. The blood urea level was $15 \mathrm{mg} / \mathrm{dl}$ and the serum creatinine level $0.3 \mathrm{mg} / \mathrm{dl}$. Serum albumin was $4.4 \mathrm{~g} / \mathrm{dl}$. The aspartate transaminase level was $37 \mathrm{U} / \mathrm{L}$

\footnotetext{
${ }^{1}$ Senior Resident, ${ }^{2}$ Assistant Professor, ${ }^{3}$ Postgraduate Trainee, ${ }^{4}$ Professor, Department of Paediatrics, Institute of Child Health, Kolkata, India

(Received on 19 November 2011: Accepted after revision on 23 December 2011)
}

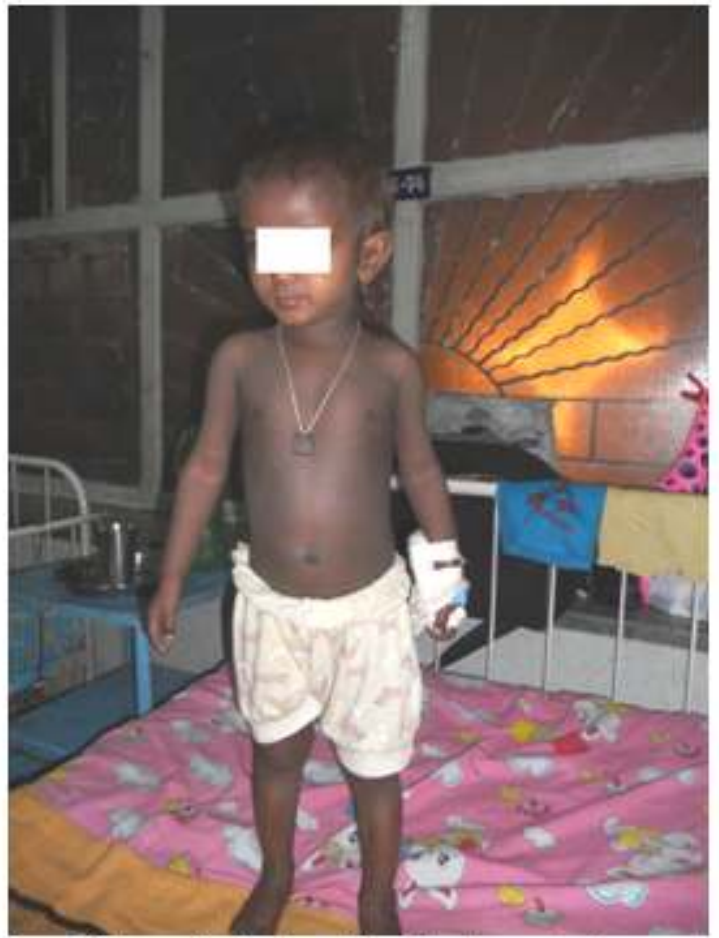

Figure 1: Baby with ashy dermatosis

and alanine transaminase level 35U/L. Serum calcium, magnesium and phosphate levels were normal. Serum sodium was $137 \mathrm{mEq} / \mathrm{L}$ and serum potassium $4.4 \mathrm{mEq} / \mathrm{L}$. The blood sugar was normal. Serum cortisol level was $10.24 \mu \mathrm{g} / \mathrm{dl}$. Gastric lavage for haemosiderin laden macrophages was negative. Serum ferritin level was $210 \mathrm{ng} / \mathrm{ml}$.

Patient was on oral supplements of vitamins in proper dose for 1 month started outside this Institute. Vitamin B12 level was $522 \mathrm{pg} / \mathrm{ml}$. Beta melanin stimulating hormone level was $0.5 \mathrm{ng} / \mathrm{dl}$.

Skin biopsy was done from hyperpigmented skin of the back and revealed mild hyperkeratosis of epidermis with patchy vacuolar alteration of basal cell layer. The papillary dermis showed aggregates of melanophages along with mild lymphocytic infiltrates in the perivascular areas. There was no 
evidence of neoplastic pathology or granulations in biopsy material.

On the basis of clinical and histopathological features a diagnosis of erythema dyschromicum perstans was made. We treated the patient with restricted sun exposure and sunscreen and oral vitamin D supplementation.

\section{Discussion}

Oswaldo Ramirez of San Salvador first described erythema dyschromicum perstans (EDP) in $1957^{2}$. It is also called dermatosis ceniciento, meaning ashy dermatosis, because of its ashy bluish gray color ${ }^{3}$. It is a distinct cutaneous eruption that may be best regarded as a form of lichen planus or lichen planus actinicus $^{4}$. It is most common in Latin America and Asia $^{3}$. It has been observed in children aged 1 year and adults aged 80 years $^{3}$. EDP is an asymptomatic eruption of oval, polycyclic, or irregularly shaped, gray-blue hyperpigmented macules on the trunk, arms, face and neck. The oral cavity and the genitals are spared ${ }^{3}$. No systemic symptoms or associations exist ${ }^{3}$.

In EDP skin biopsy usually reveals mild basal cell layer vacuolar degeneration overlying an upper dermis with a mild perivascular mononuclear cell infiltrate and increased melanophages ${ }^{3}$. This matches with our patient's histology. Many therapeutic options are available for EDP but few have been effective, except for clofazimine ${ }^{3}$.

The differential diagnosis includes carbon baby in which histopathology reveals increased pigmentation of epidermal basal layer ${ }^{5}$. Histology of our patient does not match with this. We excluded systemic conditions like Addison disease, haemochromatosis, vitamin deficiencies and post inflammatory conditions from history, clinical features and laboratory findings.

Familial progressive hyperpigmentation was ruled out in our patient as it was not present since birth and histologically melanin granules are not large ${ }^{6}$. Congenital diffuse melanosis was also ruled out as there was no reticulate pigmentation and pigmentation was not present at birth ${ }^{7}$.

\section{References}

1. Stefanato CM, Bhawan J. Diffuse hyperpigmentation of the skin: A clinicpathologic approach to diagnosis. Seminars in Cutaneous Medicine and Surgery 1997; 16: 6171.

http://dx.doi.org/10.1016/S10855629(97)80037 $\underline{-5}$

2. Ramirez CO. Los cenicientos: Problema Clinica. Memoria del Primer Congreso Centroamericano de Dermatologia 1957; 12230.

3. Schwartz RA. Erythema dyschromicum perstans. Available from:

http://emedicine.medscape.com/article/112280 7-overview

4. Naidorf KF, Chen SR. Erythema dyschromicum perstans and lichen planus. Archives of Dermatology 1982; 118(9):683-5. http://dx.doi.org/10.1001/archderm.1982.01650 210063021

5. Kaviarasan PK, Prasad P, Joe JM, Nandana N, Viswanathan P. Universal acquired melanosis (Carbon baby). Indian Journal of Dermatology Venereology and Leprology 2008; 74:38-40. http://dx.doi.org/10.4103/0378-6323.38406

6. Chernosky ME, Anderson DE, Chang JP, Shaw MW, Romsdahl MM. Familial progressive hyperpigmentation. Archives of Dermatology 1971; 103:581-2.

http://dx.doi.org/10.1001/archderm.103.6.581

7. Kint A, Qomen C, Geerte ML, Breuillard F. Congenital diffuse melanosis. Annales de Dermatologie et de Venereologie 1978; 114:116. 